\title{
DELAYED UNION OF HUMERAL SHAFT FRACTURES TREATED BY CLOSED FLEXIBLE INTRAMEDULLARY NAILING
}

\author{
JAMES W. PRITCHETT
}

From the Pacific Medical Center, Seattle

\begin{abstract}
Ten patients with humeral shaft fractures and no clinical or radiographic signs of healing after at least six weeks' immobilisation were treated by flexible intramedullary nailing using a closed retrograde technique. Bone grafting was not performed, and active movement was encouraged after operation. Nine fractures healed; the mean time to union was 10.5 weeks (range 6 to 22 weeks). One patient needed compression plating and bone grafting at 22 weeks, and another required re-operation for distal migration of the rods. There were no infections, nerve palsies or other complications. Stiffness of the shoulder which had developed during early treatment improved after operation.
\end{abstract}

Fractures of the humeral shaft usually unite satisfactorily without operation (Rush and Rush 1950; Mast $\boldsymbol{e t}$ al. 1975; Rush 1976; Epps 1984); but occasionally union is delayed and internal fixation is then considered. Compression plating provides adequate stability with a high rate of union, particularly when combined with autogenous bone grafting (Mast et al. 1975; Foster et al. 1983), but it requires an extensive dissection, with consequent risks of infection and bleeding. In addition, the radial nerve is at risk during insertion or removal of the plate (Foster et al. 1983).

With the advent of the image intensifier and improved devices, closed internal fixation has become more common, particularly in the lower extremity (Lottes 1965, 1974; Rush 1976; Clancey, Winquist and Hansen 1982). Closed flexible nailing of humeral fractures for retarded or delayed union has not been reported previously and is now described.

Union of a fracture was defined by two criteria: the absence of movement during manipulation and visible callus on radiographs. Retarded union was defined as the lack of any clinical or radiographic signs of healing at six weeks after injury, while delayed union was diagnosed if a fracture had not united within four months of injury (Stern et al. 1984).

\section{PATIENTS AND METHODS}

Closed flexible intramedullary fixation was considered for retarded or delayed union of the humerus if the fracture was of an appropriate pattern and if a satisfactory manipulative reduction was possible. Patients with estab-

J. W. Pritchett, MD

Department of Orthopaedic Surgery, Pacific Medical Center, 1200 12th Avenue South. Seattle. WA 98144 USA.

(C) 1985 British Editorial Society of Bone and Joint Surgery $0301-620 \mathrm{X} / 85 / 5172 \$ 2.00$ lished pseudarthroses, sealed medullary canals, or sepsis were not included.

Ten patients were selected for this treatment. There were six men and four women with an average age of 49.7 years (ranging from 19 to 70 years). The follow-up was for an average of 12 months (ranging from 8 to 16 months). Four of the fractures resulted from falls onto the limb, four from motor vehicle accidents, one from a pedestrian/motor vehicle collision and one from a stress fracture while pitching a baseball. Two patients had other fractures, three had significant visceral injuries, and one patient also had a brachial plexus injury and a glenohumeral dislocation. One patient had pre-operative weakness from poliomyelitis.

Fractures as high as the superior border of the insertion of pectoralis major (Case 3) and as low as $6.5 \mathrm{~cm}$ above the olecranon fossa (Case 5) were included.

Operation. Our technique is similar to the stacked nailing method of Hackethal (1961). After being anaesthetised, the patient is placed prone on the table and the entire limb is prepared and draped free. A radiolucent arm board is placed under the arm with the shoulder abducted $90^{\circ}$ and the elbow flexed to $90^{\circ}$.

The triceps muscle is split to approach the distal humerus. Using a $6.5 \mathrm{~mm}$ drill, a hole is made $1 \mathrm{~cm}$ above the olecranon fossa; care is taken to make this central to the shaft of the bone. A second hole is drilled $3 \mathrm{~cm}$ above the olecranon fossa and a high-speed burr is then used to complete a cortical window $2 \mathrm{~cm}$ long and $1 \mathrm{~cm}$ wide.

Closed reduction is then performed and checked by image intensifier in anteroposterior and lateral projections. The length of the nail has been estimated from preoperative radiographs, and is checked by placing a trial nail on top of the drapes for viewing with the image intensifier. Nails are driven up into the humeral head, and an effort is made to see that the ends of the nails 
Table I. Details of 10 patients treated by closed flexible intramedullary nailing

\begin{tabular}{|c|c|c|c|c|c|c|c|c|c|}
\hline Case & $\begin{array}{l}\text { Age } \\
\text { (years) }\end{array}$ & Sex & Side & $\begin{array}{l}\text { Time from } \\
\text { injury to } \\
\text { fixation } \\
\text { (weeks) }\end{array}$ & $\begin{array}{l}\text { Follow-up } \\
\text { (months) }\end{array}$ & $\begin{array}{l}\text { Type and } \\
\text { site* of } \\
\text { fracture }\end{array}$ & $\begin{array}{l}\text { Number of } \\
\text { nails }\end{array}$ & $\begin{array}{l}\text { Time to } \\
\text { union } \\
\text { (weeks) }\end{array}$ & Comments \\
\hline 1 & 53 & $\mathbf{M}$ & $\mathbf{R}$ & 15 & 16 & $\begin{array}{l}\text { Transverse } \\
\text { (M3) }\end{array}$ & $1(4.5 \mathrm{~mm})$ & 8 & Grade II open fracture \\
\hline 2 & 52 & $\mathbf{M}$ & $\mathrm{L}$ & 11 & 15 & $\begin{array}{l}\text { Oblique } \\
\text { (P3-M3) }\end{array}$ & $\begin{array}{l}2(4.5 \mathrm{~mm}) \\
4(3.2 \mathrm{~mm})\end{array}$ & 20 & Re-operation required for migration of nail \\
\hline 3 & 63 & $\mathbf{M}$ & L & 9 & 14 & $\begin{array}{l}\text { Transverse } \\
\text { (P3) }\end{array}$ & $2(3.2 \mathrm{~mm})$ & 6 & Poliomyelitis \\
\hline 4 & 44 & $\mathbf{M}$ & $\mathbf{R}$ & 11 & 13 & $\begin{array}{l}\text { Comminuted } \\
\text { (M3) }\end{array}$ & $2(3.2 \mathrm{~mm})$ & 30 & Stress fracture plated at 22 weeks \\
\hline 5 & 23 & $\mathbf{M}$ & $\mathrm{L}$ & 22 & 12 & $\begin{array}{l}\text { Transverse } \\
\text { (M3-D3) }\end{array}$ & $3(3.2 \mathrm{~mm})$ & 9 & \\
\hline 6 & 47 & $\mathbf{F}$ & L & 6 & 9 & $\begin{array}{l}\text { Oblique } \\
\text { (M3) }\end{array}$ & $2(3.5 \mathrm{~mm})$ & 11 & Previous fracture \\
\hline 7 & 60 & $\mathrm{~F}$ & $\mathbf{L}$ & 10 & 11 & $\begin{array}{l}\text { Oblique } \\
\text { (P3-M3) }\end{array}$ & $3(3.2 \mathrm{~mm})$ & 7 & \\
\hline 8 & 70 & $\mathbf{F}$ & $\mathbf{L}$ & 13 & 8 & $\begin{array}{l}\text { Segmental, } \\
\text { transverse } \\
\text { (P3-D3) }\end{array}$ & $3(3.2 \mathrm{~mm})$ & 8 & Intra-operative fracture \\
\hline 9 & 19 & $\mathbf{M}$ & $\mathbf{R}$ & 7 & 10 & $\begin{array}{l}\text { Comminuted, } \\
\text { short oblique } \\
\text { (M3-D3) }\end{array}$ & $3(3.2 \mathrm{~mm})$ & 10 & \\
\hline 10 & 66 & $\mathbf{F}$ & $\mathbf{R}$ & 12 & 12 & $\begin{array}{l}\text { Oblique } \\
\text { (M3) }\end{array}$ & $2(3.5 \mathrm{~mm})$ & 14 & \\
\hline
\end{tabular}

* P3, proximal third of humerus; M3, middle third (mid-shaft); D3, distal third

diverge into the head. Once a nail has been inserted it must be held with a clamp or hook to prevent migration through the soft humeral head while additional nails are being inserted.

The shape, size and number of nails are determined by the fracture pattern and the size of the medullary canal. The nails are contoured to correct any deformity and to secure firm fixation. An attempt is made to fill the medullary canal. Initially, we used nails with diameters of $4.5 \mathrm{~mm}$, but found that the canal could accommodate only two nails. Later $3.2 \mathrm{~mm}$ nails were used and three or four nails could then be inserted. The smaller nails also have the advantage that they are more easily bent.

The ends of the nails should protrude just enough to make attachment of the extractor possible. They should not be buried entirely within the medullary canal since they would then have less secure fixation and would be more difficult to remove.

After operation the arm is elevated for $\mathbf{4 8}$ hours, after which gentle active movement of the elbow and shoulder is encouraged.

\section{RESULTS}

Closed retrograde flexible intramedullary nailing of the humerus was performed in 10 patients with retarded or delayed union. Details of the fractures are given in Table I. Four of the fractures were oblique, three were transverse, two were comminuted and one was segmental. The average operating time was 90 minutes (range 30 to 170 minutes), and blood loss averaged $150 \mathrm{ml}$ (range $50 \mathrm{ml}$ to $400 \mathrm{ml}$ ). None of the fracture sites was exposed and no bone grafts were used.

The number of nails ranged from one to four, and the time to union averaged 10.5 weeks (range 6 to 22 weeks). There were no infections or any fractures where the nails entered the bone. One patient (Case 8) sustained a fracture of the proximal humerus while the shoulder was being manipulated under anaesthesia before being nailed (Figs 1 and 2); this fracture, as well as the shaft fracture, was then nailed and both healed uneventfully (Figs 3 and 4).

One patient (Case 2) required re-operation to replace nails that backed out eight weeks after insertion; the two original $4.5 \mathrm{~mm}$ nails were exchanged for four $3.2 \mathrm{~mm}$ nails. The fracture subsequently united, but the nails again became prominent and required removal. Two other patients complained of occasional aching in the area of nail insertion, but did not require analgesics.

There were no nerve palsies as a result of the operation. One patient (Case 6) had a brachial plexus injury pre-operatively but this resolved after operation.

\section{DISCUSSION}

The image intensifier and other technical advances have made closed methods of fracture fixation increasingly popular. Successful closed treatment of delayed union of the tibia, using Küntscher and Lottes nails, has been described. When nails which require reaming are used, 


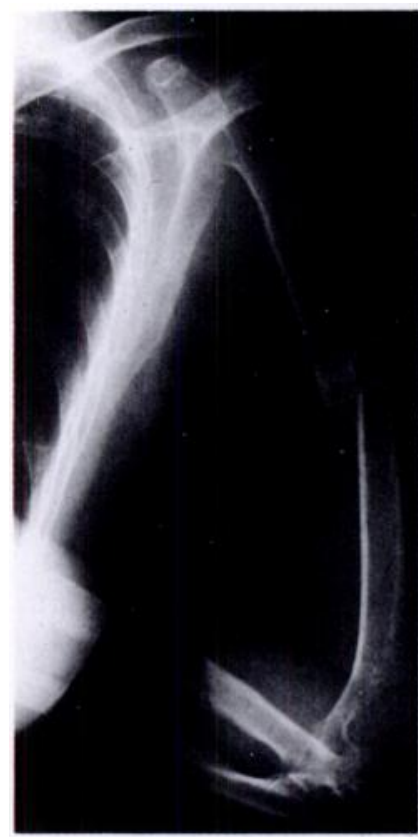

Fig. 1

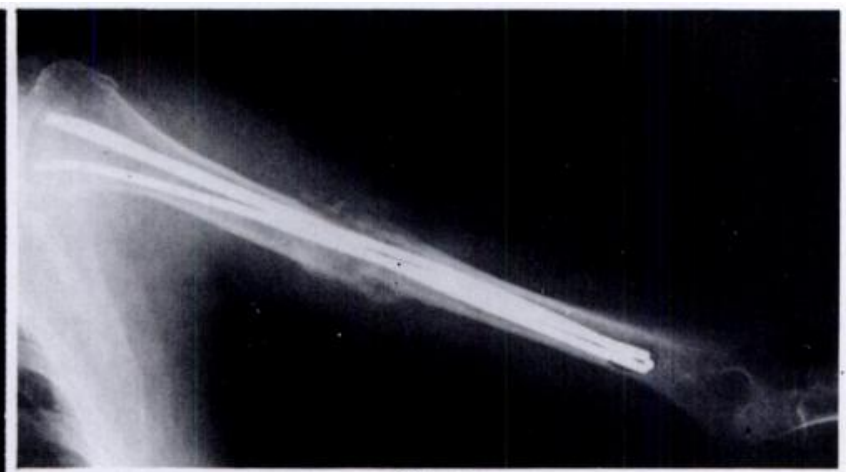

Fig. 2

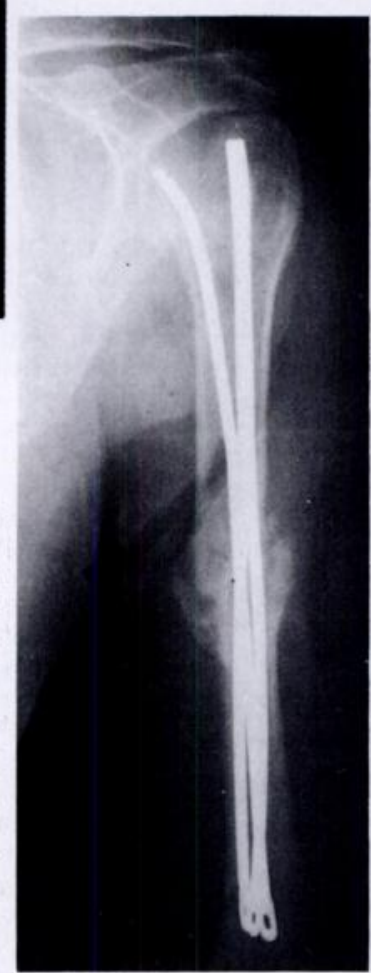

Fig. 3

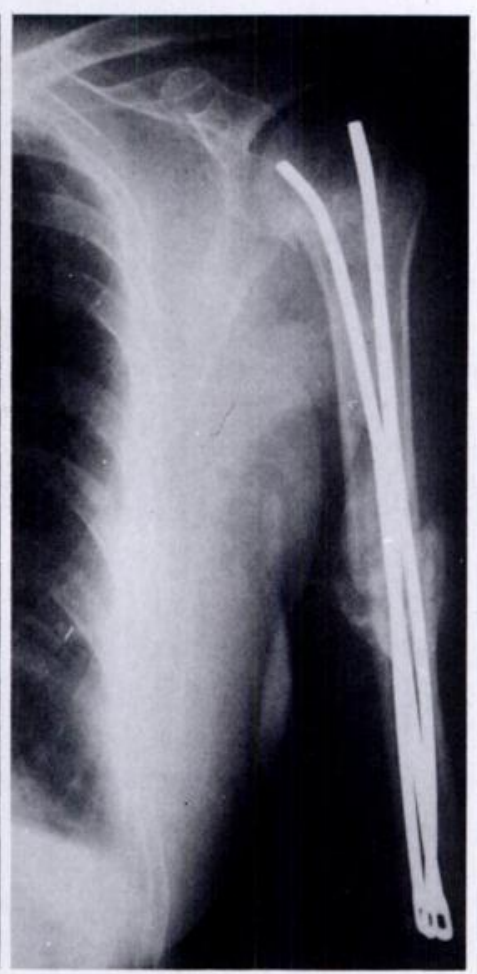

Fig. 4 the bone fragments produced by this may act as grafts, so that additional bone is rarely needed (Clancey, Winquist and Hansen 1982).

The principles of dynamic intramedullary nailing are very important and their correct application is crucial to success. Three-point fixation is essential for maximum stability. A curved nail in the relatively straight humerus can achieve dynamic fixation whereas a straight nail can not. Retrograde insertion of the nail assures three-point fixation and also avoids the morbidity of an incision at the shoulder (Rush 1976; Durbin, Gottesman and Saunders 1983; Foster et al. 1983).

There are many reports of significant morbidity after operative treatment of fractures of the humeral shaft (Mast et al. 1975; Epps 1984), and complication rates of intramedullary fixation as high as $67 \%$ have been reported (Stern et al. 1984). However, good results with minimum morbidity have been achieved when proper techniques have been used (Rush 1976; Foster et al. 1983).

In a recent report on intramedullary fixation, delayed union or non-union occurred in only $9 \%$ of closed or so-called semi-open reductions as compared with an incidence of $39 \%$ after open reductions; moreover, retrograde insertion contributed to a higher success rate (Stern et al. 1984). Durbin, Gottesman and Saunders (1983) reported a union rate of $92 \%$ with only minor complications using Hackethal's (1961) technique of retrograde insertion of Steinmann pins, while Hall and Pankovich (1982) reported 100\% union of acute humeral shaft fractures treated with Ender nails.

Nine of the 10 fractures we report healed, giving a success rate of $90 \%$. Nailing was unsuccessful in one patient (Case 4, Fig. 5), who had initially been treated with coaptation splints for 11 weeks. After intramedullary nailing (Fig. 6) callus was developing but the fracture 


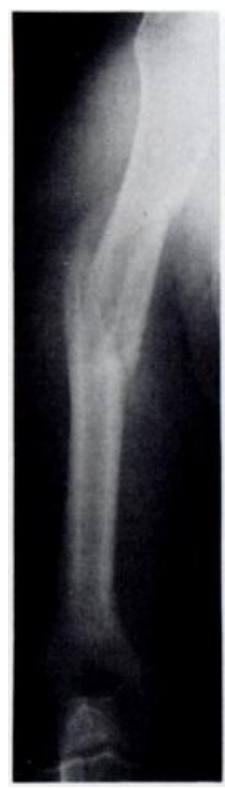

Fig. 5

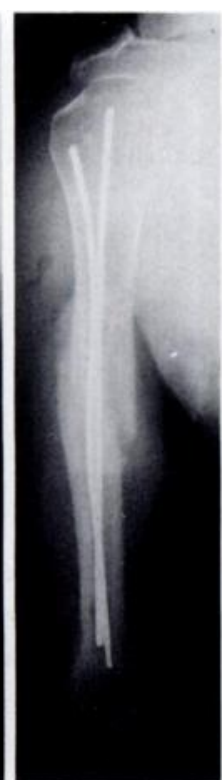

Fig. 6

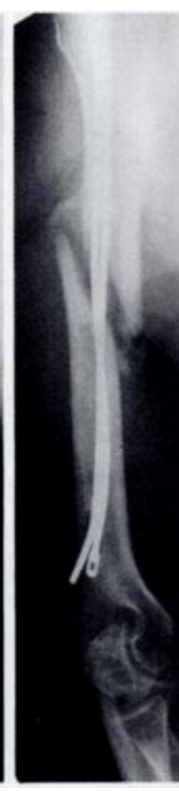

Fig. 7

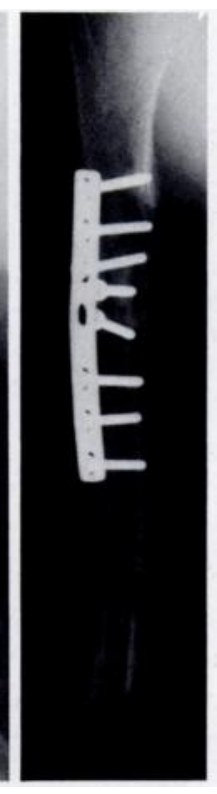

Fig. 8
Case 4. A 44-year-old man fractured his right humeral shaft. After 11 weeks in coaptation splints he had pain and no callus at the fracture site (Fig. 5). Figure 6-Ten weeks after operation there was no pain and some callus at the fracture site. Figure 7-Twenty-two weeks after operation he had slight mild pain; the nails were distracting the fracture site. Figure 8-Compression plating and autogenous bone grafting was performed and at 30 weeks the fracture had united.

had not consolidated after 22 weeks, while the nails appeared to distract the fracture site (Fig. 7). Revision nailing or nail removal and functional bracing were considered, but the treatment selected was compression plating and bone grafting (Fig. 8).

Painful adhesive capsulitis of the shoulder has been reported in up to $56 \%$ of patients treated with distally directed nails (Stern et al. 1984). This complication is not seen after retrograde insertion, although most patients with retarded or delayed union have shoulder stiffness from their previous immobilisation. Restricted movement of the elbow has not been a problem after retrograde insertion of Rush pins, Steinmann pins, or Ender nails (Rush 1976; Hall and Pankovich 1982; Durbin, Gottesman and Saunders 1983).

Closed retrograde intramedullary fixation for retarded union, delayed union and non-union of the humerus has not been extensively described but is an effective technique in selected cases. Open fixation with downward insertion of Rush pins and bone grafting has been reported to be successful for retarded union and delayed union, but not for non-union (Rush 1976; Stern et al. 1984). Lottes (1984) has used closed, downward insertion of a flexible triflanged nail with success. Our patients did well after closed retrograde nailing, but we did not include cases with established non-union; these may be more successfully treated by compression plate fixation.

\section{REFERENCES}

Clancey GJ, Winquist RA, Hansen ST Jr. Non-union of the tibia treated by Küntscher intramedullary nailing. Clin Orthop 1982; 167: 190-6.

Durbin RA, Gottesman MJ, Saunders KC. Hackethal stacked nailing of humeral shaft fractures: experience with 30 patients. Clin Orthop 1983;179: 168-74.

Epps CH Jr. Fractures of the shaft of the humerus. In: Rockwood CA $\mathrm{Jr}$, Green DP, eds. Fractures in adults. Philadelphia: JB Lippincott, 1984;1:653-74.

Foster RJ, Dixon GL Jr, Bach AW, Appleyard R. Internal fixation of humeral shaft lesions: indications and results. Orthop Trans 1983; 7:69.

Hackethal KH. Die Bündel: Nagelung Boelin. Berlin etc: SpringerVerlag, 1961:134.

Hall RF Jr, Pankovich AM. Technique and results of closed intramedullary rodding of diaphyseal fractures of the humerus. Orthop Trans 1982;6:359.

Lottes JO. Treatment of delayed or nonunion fractures of the tibia by a medullary nail. Clin Orthop 1965;43:111-28.

Lottes JO. Medullary nailing of the tibia with the triflange nail. Clin Orthop 1974; 105: 53-66.

Mast JW, Spiegel PG, Harvey JP Jr, Harrison C. Fractures of the humeral shaft: a retrospective study of 240 adult fractures. Clin Orthop 1975;112:254-62.

Rush LV. Atlas of Rush pin technics: a system of fracture treatment. 2nd ed. Meridian, Mississippi: Berivon, 1976.

Rush LV, Rush HL. Intramedullary fixation of fractures of humerus by longitudinal pin. Surgery 1950;27:268-75.

Stern PJ, Mattingly DA, Pomeroy DL, Zenni EJ, Kreig JK. Intramedullary fixation of humeral shaft fractures. J Bone Joint Surg $[A m] 1984 ; 66-A: 639-46$. 